\title{
Risk Evaluation of Sewage Treatment PPPABS Projects Using Combination Weight Method and D-S Evidence Theory
}

\author{
Hui Zhao (D), Zehui Bu, and Shengbin Ma \\ School of Management Engineering, Qingdao University of Technology, Qingdao 266520, China \\ Correspondence should be addressed to Hui Zhao; zhaohui43@126.com
}

Received 4 May 2020; Accepted 28 May 2020; Published 3 July 2020

Guest Editor: Lei Xie

Copyright (C) 2020 Hui Zhao et al. This is an open access article distributed under the Creative Commons Attribution License, which permits unrestricted use, distribution, and reproduction in any medium, provided the original work is properly cited.

\begin{abstract}
In order to make up for the shortage of public-private partnership (PPP) model, more and more sewage treatment PPP projects have adopted the asset-backed securitization (ABS) model. To ensure success of sewage treatment PPPABS projects, risk evaluation, which has remained scarcity and unscientific, is becoming an urgent problem to be solved. Firstly, this paper identifies critical risk factors by literature analysis and expert interview. The final risk system is established from the perspectives of macrorisks, basic asset risks, transaction structure risks, operational risks, and other risks, which include 17 second risk factors. Then, the overall risk evaluation method is proposed based on combination weight method and Dempster-Shafer (D-S) evidence theory. Next, Beijing capital Co. Ltd. sewage treatment PPPABS project as a case is employed to verify the feasibility and effectiveness of the proposed method. Finally, awareness of existing risks, suggestions from law risk, quality risk, underwriting and issue risk, and credit enhancement are provided for sewage treatment PPPABS projects. All above studies are expected to provide helpful references for evaluating overall risk of sewage treatment PPPABS projects.
\end{abstract}

\section{Introduction}

With the global emphasis on environmental protection and sustainable development, water saving and sewage treatment are becoming necessary and urgent issues $[1,2]$. The water environment is the basis for the survival of residents. In addition, the water environment treatment is an important task for the government to build a harmonious society [3]. However, the current capacity for sewage treatment is relatively low. In order to curb the adverse effects of environmental pollution due to the uncontrolled discharge of sewage, effective measures must be taken to ensure that the discharge of sewage meets the required standards [4]. Sewage treatment projects play a key role in environmental protection and sustainable development plans as an effective way to reduce sewage and protect environment [5]. However, such progress is constrained by a shortage of funds. Constructing a sewage treatment project usually costs a large capital investment and has an extensive project period. Only relying on government investment in sewage treatment projects is very difficult if the local government has a high level of debt [6].
The public-private partnership (PPP) model has been adopted and developed rapidly in sewage treatment projects in recent years. As a cooperative mechanism, PPP enables the government and the private sector, with different degrees of rights and responsibilities, to provide more efficient infrastructure products and public services through mutually complementary cooperation. In Germany, one-third of all sewage treatment projects employ the PPP model. During 2013, the White House Council on Environmental Quality held a seminar where various representatives suggested that local government should apply the PPP model to provide financial resources for sewage disposal. From then on, many sewage treatment projects in America have applied the PPP model [7]. Especially in China, a large amount of sewage treatment projects have adopted the PPP model. The number of sewage treatment PPP projects entering project library of China Public Private Partnerships Center (CPPPC) has soared to 951 during 2014-2018. However, in practice, PPP projects have problems such as long operating cycle, large investment, high financing cost, poor liquidity of assets, and unsound exit mechanism, which make the private 
participants very cautious, and the actual implementation rate of the project is not high [6]. Taking the 951 sewage treatment PPP projects in China, for example, less than 10 percent of the 951 projects enter the implementation phase.

To overpass these outstanding barriers and further enrich the financing innovation, asset-backed securitization (ABS) mode supported by government policies is widely recognized and rapidly developed in PPP projects [8]. Especially in China, China's National Development and Reform Commission, Ministry of Finance, and other relevant departments have issued a series of documents for encouraging infrastructures with PPP mode to adopt ABS [9]. Until 20 April, 2020, 21 PPP projects, including sewage treatment PPP projects, implemented ABS and the issuance scale exceeded 2.95 billion dollars. Asset-backed securitization of sewage treatment PPP projects is becoming an important channel to solve the development dilemma of sewage treatment projects.

Asset-backed securitization has been used in the capital market for many years, but the combination of asset-backed securitization and PPP model is still a new pattern. What is the PPPABS? It is not until 2016 that PPPABS was first defined in China. Public-private partnership asset-backed securitization (PPPABS) projects usually involve huge capital, exclusive capital, and many participants. Moreover, the PPPABS projects take the project assets and their income as the only or main source of repayment and have the characteristics of nonrecourse or limited recourse. All these characteristics determine the complexity and particularity of the risks in PPPABS projects. However, research on risk evaluation of PPPABS projects is limited and unscientific. Therefore, to ensure the success of sewage treatment PPPABS projects, it is very important and necessary to achieve what risk factors affect sewage treatment PPPABS projects and propose an appropriate method to evaluate overall risk of sewage treatment PPPABS projects.

At present, risk factors and management are the focus research of PPPABS projects by the researchers. Some scholars have focused on the composition of risk factors of PPPABS projects [10-13]. How to eliminate the risk before the occurrence and how to control the risk after the occurrence? Others have made a comprehensive analysis from various aspects or perspectives and put forward some effective preventive measures and risk control theory [13-15]. However, through reviewing the existing literature, it is found that no one has constructed the risk evaluation system for sewage treatment PPPABS projects. It is also found that the management of PPPABS projects is almost qualitative and lacks quantitative research, especially in evaluating the overall risk of sewage treatment PPPABS projects. How to overcome these issues? The present study can fill this research gap.

This paper makes the following practical and academic contributions. Firstly, aiming at the problem of imperfect risk evaluation system for sewage treatment PPPABS projects, we construct a risk evaluation system specially applicable to sewage treatment PPPABS projects through literature review and expert interview. Secondly, in view of the insufficiency of the current methods of determining the risk factor weight in PPPABS projects, to be more scientific and reasonable, we propose a combination weight method (combining G1 method and the entropy method), which lays a solid foundation for the next scientific risk evaluation. Thirdly, to ensure a more scientific risk evaluation, we put forward an effective quantitative evaluation method based on Dempster-Shafer (D-S) evidence theory, which enriches the research on the overall risk evaluation of sewage treatment PPPABS projects and enables participants to better grasp the overall risk in sewage treatment PPPABS projects. Finally, combined with the case, we present some practical and feasible suggestions which provide a valuable reference for the smooth development of PPPABS projects.

The remainder of this study is organized as follows. The status of risk research in PPPABS projects is reviewed in Section 2. In Section 3, we construct research framework of this work, identify risk factors, determine weights of risk factors using the combination weight method, and propose an approach with D-S evidence theory for the overall risk evaluation of sewage treatment PPPABS projects. In Section 4 , the feasibility and effectiveness of the proposed methods are verified by a case study. We discuss the results of the case and put forward some feasible suggestions in Section 5. Finally, the conclusions and further work are presented in Section 6.

\section{Literature Review}

PPPABS takes the future stable cash flow of PPP projects or specific asset portfolio as the basic assets of asset-backed securitization. Through structural design, financing is realized when the basic assets are turned into liquid securities to flow and transferred in the capital market [9]. PPPABS is a new financing pattern emerging in the area of PPP infrastructure projects. Therefore, there is limited literature on risk research of PPPABS projects.

\subsection{Identification of Critical Risk Factors for PPPABS Projects.} Risk factors of PPPABS projects are increasingly concerned by researchers. Several scholars have roughly studied the risk factors in PPPABS projects [10]. For ease of analysis, a few scholars have provided specific risk factors in PPPABS projects. Suleman Baig and Moorad Choudhry collected and analyzed various risk characteristics during the 2007-2008 subprime crisis. The main risk factors of PPPABS projects were found to be the shadow banking system, the lack of effective financial supervision, the moral hazard of speculators, the lack of rationality in the setting of leverage level, the lack of ability of rating agencies, and the lack of risk warning ability [11]. Hou Yufeng, based on the whole process of PPPABS projects, pointed out that the risks mainly included the risk of basic assets, the risk of original stakeholders, the risk related to the guarantor, the risk of rating, the risk of performance of other participating institutions, the risk of market, the risk of information disclosure, and the risk of imperfect policies and laws [12]. Liu et al. constructed the risk evaluation system of PPPABS projects by using the analytic hierarchy process (AHP), 
which mainly included four major aspects: environmental risk, credit risk, technical risk, and operational risk [13]. Summarizing the research on risk identification, we find that most of the existing studies identify risks from the perspective of PPPABS projects and no detailed differentiation studies are conducted, such as identifying risk factors for sewage treatment PPPABS projects and for expressway PPPABS projects, which lead to the lack of applicability of the existing evaluation system.

2.2. Risk Management of PPPABS Projects. How to eliminate the risk before the occurrence and how to control the risk after the occurrence? This is another focus of scholars' attention and research. Through a thorough analysis of the financial crisis, $\mathrm{Pu}$ Liu and Yingying Shao proposed five improvement measures. Firstly, it was necessary to management comprehensive investment risks. Secondly, the evaluation method of enterprises should be based on marketization. Thirdly, the evaluation, prevention, and control of liquidity risk should keep pace with the time. Fourthly, the rating methods of credit rating agencies should not remain unchanged and timely adjustments should be made. Finally, the information of market participants should be fully disclosed [14]. After analyzing the risks of many PPP financing cases, Terry Lyons believed that it was necessary to analyze the risk that may exist in the process of PPP project asset-backed securitization. In the process of asset-backed securitization, the risk sharing method could better reduce the risk of PPPABS projects [15]. Moreover, as for risk evaluation methods of PPPABS projects, several scholars have proposed a few methods. Liu et al. constructed the risk evaluation system of PPPABS projects by using the analytic hierarchy process (AHP) and also used AHP to evaluate overall risk of PPPABS projects [13]. Taking the asset-backed securities of the parking PPP project in Yanjiang district of China's Ziyang city as an example, Fan Yulin used the fuzzy comprehensive evaluation method to conduct the risk evaluation research. It can be seen from the existing literature that scholars focus on qualitative research and a few scholars have carried out quantitative analysis. However, the AHP method and the fuzzy comprehensive evaluation method are too subjective for evaluation and the evaluation effect is poor [16].

From the literature analysis, current risk research on PPPABS projects is limited. The existing risk evaluation system cannot be fully applied to sewage treatment PPPABS projects. It needed to be rebuilt. Moreover, existing quantitative methods are unscientific. It is also necessary to find an appropriate evaluation method. These are the main contents of this paper.

\section{Methodology}

In this study, a combination of literature analysis and expert interview is used to generate the critical risk factors for sewage treatment PPPABS projects. With the data collected from a questionnaire, combination weight method (combining G1 method and the entropy method) is applied to determine weight of each critical risk factor. Then, we evaluate overall risk based on D-S evidence theory. To test the effectiveness and scientificity of the proposed method, a case study of one sewage treatment PPPABS launched in China is used to demonstrate the application. Finally, some suggestions are given based on the results of the case. The research framework is shown in Figure 1. Our purpose is to effectively evaluate the overall risk of sewage treatment PPPABS projects after identifying the critical risk factors affecting sewage treatment PPPABS projects.

\subsection{Identification of Critical Risk Factors for Sewage Treatment} PPPABS Projects. Literature analysis and expert interview are the main methods used in risk factor identification [17]. Based on the mainstream methodologies, literature analysis and expert interview are adopted to identify the critical risk factors of sewage treatment PPPABS projects. In addition, the introduction of asset-backed securitization into PPP projects is an innovation. Scholars' research in this field is limited. In 2016, China defined PPPABS for the first time and provided policy support. PPPABS projects are developing rapidly in China. In view of the fact that there are many PPPABS projects and also many researchers and practitioners in China, the paper selected experts in China to collect data.

3.1.1. Literature Analysis. In this study, the risk components of PPPABS of sewage treatment project are collected by longitudinal and crosswise designs. Through literature summary, 5 first-level risk factors in the terms of "macrorisks," "basic asset risks," "transaction structure risks," "operational risks," and "other risks" are put forward. A total of 17 second-level risk factors in sewage treatment PPPABS projects are also offered from the existing journal papers as listed in Table 1. After that the initial risk system is further modified in the next expert interview.

3.1.2. Expert Interview. In our study, expert interview method is applied twice. In the first round, we construct an interview guidelines designed for the interview survey. The guidelines consist of 19 columns. The first 18 columns are composed of 18 risk factors in Table 1, while the last 19 columns are blank. Experts can delete these 18 risk factors or add new risks in the blank column according to their own opinions. The final risk system of sewage treatment PPPABS projects is obtained by adding or removing relevant risk factors. In the second round, experts compare and assign the risk factors in the final risk system. In the second round, according to the final risk system obtained in the first round, another interview guidelines are constructed. Experts compare and assign the risk factors in the final risk system.

(1) Select Experts. In order to optimize the selected risk factors and reasonably determine the value of each risk factor of sewage treatment PPPABS projects, the selected experts must satisfy at least one of the following conditions: the professor in a very famous university with more than three years of experience in the PPPABS field; the expert actively participating in PPPABS training for government agencies and private 


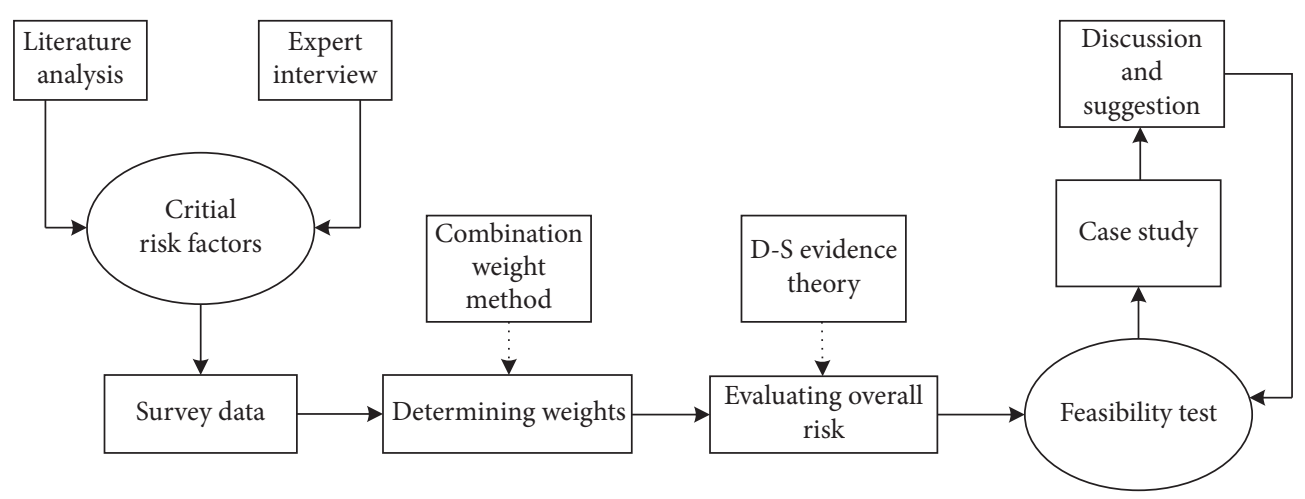

FIgURE 1: Research framework.

TABLE 1: Initial risk system of the sewage treatment PPPABS projects.

\begin{tabular}{|c|c|c|}
\hline First-level risk factors & Second-level risk factors & References \\
\hline \multicolumn{3}{|l|}{ Factor 1: macrorisks } \\
\hline 1 & Interest risk & Farooquee [8] \\
\hline 2 & Law risk & Austin et al. [10] \\
\hline 3 & Inflation risk & Lyons and Martin [15] \\
\hline 4 & Political risk & Liu et al. [13] \\
\hline \multicolumn{3}{|l|}{ Factor 2: basic asset risks } \\
\hline 5 & Quality risk & Liang $[11]$ \\
\hline 6 & Unsold risk & Hou [12] \\
\hline 7 & Cash flow prediction deviation risk & Hou [12] \\
\hline \multicolumn{3}{|c|}{ Factor 3: transaction structure risks } \\
\hline 8 & Bankruptcy isolation risk & Liu and Shao [14] \\
\hline 9 & Transaction structure rationality risk & Austin et al. [10] \\
\hline 10 & Prepayment risk & Liu et al. [13] \\
\hline 11 & SPV bankruptcy risk & Hou [12] \\
\hline \multicolumn{3}{|c|}{ Factor 4: operational risks } \\
\hline 12 & Underwriting and issue risk & Lyons and Martin [15] \\
\hline 13 & Service provider risk & Hou [12] \\
\hline 14 & Trustee risk & Farooquee $[8]$ \\
\hline \multicolumn{3}{|l|}{ Factor 5: other risks } \\
\hline 15 & Government contract fulfillment risk & Liu et al. [13] \\
\hline 16 & Ethical risk & Hou [12] \\
\hline 17 & Credit enhancement & Lu et al. [9] \\
\hline 18 & Credit rating risk & Hou [12] \\
\hline
\end{tabular}

sectors; the general manager at a large consulting company with multiple PPP or ABS project practical experiences; the experienced professional in a construction management company who has been involved in a number of infrastructure PPP or ABS projects; the lawyer from a famous law firm with the ability to provide the legal advice for PPPABS practice; and the government official in at least the municipal level responsible for facilitating PPPABS projects.

Most of the experts have rich practical experience in PPP or ABS and act as project evaluation experts in the database of China's Ministry of Finance (MOF) and the China assetbacked security (CNABS). Four trained graduate students assist in conducting expert interviews. Finally, according to the selection criteria, ten experts are selected. And work units and related positions are shown in Table 2.

(2) Experts in the First Round. In the first round of expert interview, the opinion is put forward that inflation risk can be ruled out from the initial risk system because the marketoriented economy system is gradually formed. In addition, with public participation, transparent and rigorous governance systems for public infrastructure or services have been established. Ethical risk can also be excluded. Moreover, considering the main content of the special purpose vehicle (SPV) bankruptcy risk overlapping the transaction structure rationality risk's connotation, the transaction structure rationality risk can also be expunged. Additionally, given the long span and preconditions for the securitization of basic asset in sewage treatment PPPABS projects, the majeure risk and basic asset compliance risk should be added. In summary, through expert interviews, three risk factors, "inflation risk," "transaction structure rationality risk," and "ethical risk" are eliminated, and two risk factors, "majeure risk" and "basic asset compliance risk" are added. Combining the literature and opinions of 10 experts, a final risk system of sewage treatment PPPABS projects is provided in Table 3. 
TABLE 2: Information of the experts.

\begin{tabular}{lcc}
\hline No. & Work unit & Position \\
\hline 1 & Tsinghua University & Professor \\
2 & Pianjin University & Professor \\
3 & Qingdao Engineering Consulting Institute & Professional advisor \\
4 & China Great Wall Asset Management Co. Ltd. & Professional advisor \\
5 & Qingdao City Financing Department & Official \\
6 & China Construction Eighth Engineering Division Co. Ltd. & General manager \\
7 & Zhong Yin Law Firm & Lawyer \\
8 & China Orient Asset Management Co. Ltd. & Professional advisor \\
9 & Chongqing University & Professor \\
10 & China Cinda Asset Management Co., Ltd. & Professional advisor \\
\hline
\end{tabular}

TABLE 3: Final risk system of sewage treatment PPPABS projects.

\begin{tabular}{|c|c|c|}
\hline First-level risk factors & Second-level risk factors & References \\
\hline$A_{1}:$ macrorisks & $\begin{array}{c}C_{1}: \text { interest risk } \\
C_{2}: \text { law risk } \\
C_{3}: \text { political risk }\end{array}$ & $\begin{array}{c}\text { Farooquee [8] } \\
\text { Austin et al. [10] } \\
\text { Liu et al. [13] }\end{array}$ \\
\hline$A_{2}$ : basic asset risks & $\begin{array}{c}C_{4}: \text { quality risk } \\
C_{5}: \text { unsold risk } \\
C_{6}: \text { cash flow prediction deviation risk } \\
C_{7}: \text { basic asset compliance risk }\end{array}$ & $\begin{array}{l}\text { Liang [11] } \\
\text { Hou [12] } \\
\text { Hou [12] } \\
\text { Experts }\end{array}$ \\
\hline$A_{3}:$ transaction structure risks & $\begin{array}{c}C_{8}: \text { bankruptcy isolation risk } \\
C_{9}: \text { prepayment risk } \\
C_{10}: \text { SPV bankruptcy risk }\end{array}$ & $\begin{array}{c}\text { Liu and Shao [14] } \\
\text { Liu et al. [13] } \\
\text { Hou [12] }\end{array}$ \\
\hline$A_{4}:$ operational risks & $\begin{array}{c}C_{11}: \text { underwriting and issue risk } \\
C_{12}: \text { service providers risk } \\
C_{13}: \text { trustee risk }\end{array}$ & $\begin{array}{c}\text { Lyons and Martin [15] } \\
\text { Hou [12] } \\
\text { Farooquee [8] }\end{array}$ \\
\hline$A_{5}:$ other risks & $\begin{array}{c}C_{14}: \text { government contract fulfillment risk } \\
C_{15}: \text { majeure risk } \\
C_{16}: \text { credit enhancement } \\
C_{17}: \text { credit rating risk }\end{array}$ & $\begin{array}{c}\text { Liu et al. [13] } \\
\text { Experts } \\
\text { Lu et al. [9] } \\
\text { Hou [12] }\end{array}$ \\
\hline
\end{tabular}

The main risks are described as follows. $\left(A_{1}\right)$ Macrorisks: at present, laws and policies on PPPABS are mainly industrial regulations and local regulations. The legal and policy documents issued to regulate PPPABS are easily affected by the development of social economy, market changes, and technological progress, thus affecting the issuance of PPP asset securitization. Moreover, in the process of asset securitization, due to the decrease in value or the uncertainty of future returns caused by interest rate changes, such uncertainty will also become interest rate risk. $\left(A_{2}\right)$ Basic asset risks: basic assets of PPPABS must meet certain conditions, or the ABS may have security risks in the first place. The risks related to the basic assets include quality risk (whether it is a high-quality basic asset), unsold risk (are they really for sale?), cash flow prediction deviation risk (whether the cash flow forecast is accurate), and basic asset compliance risk (whether the basic assets are legal). $\left(A_{3}\right)$ Transaction structure risks: the risks in this aspect are mainly analyzed from the aspect of transaction structure. It mainly analyzes whether bankruptcy isolation can be realized, prepayment can be made, and the stability of SPV can be built. $\left(A_{4}\right)$ Operational risks: the risks in this area are mainly in the operational phase. It mainly includes whether the underwriting and issuance can be realized smoothly, the behaviors of service providers that harm the interests of investors, and whether the management level of the trustee can meet the requirements. $\left(A_{5}\right)$ Other risks: other risks refer to the risks worthy of attention in addition to the above four categories. The risks in this aspect include government contract fulfillment risk, the majeure risk such as war and natural disaster, whether the credit enhancement can be realized at the critical moment and whether the value of assets will be affected due to the credit rating.

(3) Experts in the Second Round. In the second round of expert interview, the questionnaire survey of risk factor scores is designed according to the final risk system of sewage treatment PPPABS projects. A questionnaire survey is conducted to obtain the objectives of this study. Based on the need of the research methods in Section 3, experts are required to endow each risk value according to risk degree [1] in Table 4 and also to give the level of each risk so as to calculate occurrence probability of each risk. The professional experience and competence of the experts can guarantee the reliability of the data. The data obtained from the questionnaire survey lay a solid foundation for the overall risk evaluation.

3.2. Determine Weight of Each Critical Risk Factor with Combination Weight Method. Common objective weight methods include the entropy method and principal 
TABLE 4: Risk evaluation criteria.

\begin{tabular}{lc}
\hline Risk level & Corresponding risk value range \\
\hline Very high $\left(x_{1}\right)$ & {$[0.8,1.0]$} \\
High $\left(x_{2}\right)$ & {$[0.6,0.8)$} \\
Moderate $\left(x_{3}\right)$ & {$[0.4,0.6)$} \\
Low $\left(x_{4}\right)$ & {$[0.2,0.4)$} \\
Very low $\left(x_{5}\right)$ & {$[0,0.2)$} \\
\hline
\end{tabular}

component analysis method. However, objective weight methods rely on statistical and mathematical methods and ignore the human factors in the decision-making process, which makes it not close to the reality. Common subjective weight methods include AHP method and Delphi method. However, subjective weight methods depend too much on expert opinions, which are limited by personal knowledge and have certain limitations. Based on the shortcomings of subjective and objective weight methods, some scholars propose the combination weight method. At present, the combination weight method is becoming a trend [18].

Objective weight method: the entropy determines the weight of each factor by the entropy value which reflects the information of each factor. However, this method has the disadvantage of not taking into account the mutual influence of each factor. Subjective weight method: G1 fully considers the mutual influence of each factor and is essentially the analysis of order relation. Therefore, this paper combines G1 method with entropy method, which is not divorced from the subjective reality and based on certain objective data. It not only retains the advantages of the two methods, but also makes up for the shortcomings of each method. In addition, the key step of this combined method is to determine the proportion of the weight determined by G1 and the weight determined by the entropy in the comprehensive weight. The commonly method to determine the subjective and objective weight proportion is the Delphi method. However, the Delphi method has too many human factors to be scientific [18]. This paper is based on Lagrange theory to determine the proportion of subjective and objective weights.

3.2.1. Subjective Weights Based on G1 Method. G1 method is an improved subjective weight method proposed by professor Guo Yajun on the theoretical basis of analytic hierarchy process (AHP) [18]. The G1 method mainly refers to a factor preference method that first sorts the importance of the measurement factors according to the expert opinions, then compares and judges the adjacent measurement factors one by one, and finally quantitatively assigns values on this basis. It can fully reflect the subjective opinions of experts, and its order of importance will not change with the change of factors. Therefore, this paper adopts the G1 method to achieve the subjective weights of risk factors, and the specific steps are as follows:

Step 1. Rank the risks in accordance with their importance. For the risk factor set $\left(c_{1}, c_{2}, \ldots, c_{n}\right)$, the unique ordering relationship can be obtained.

Step 2. Determine the relative importance $r_{k}=\omega_{k-1} / \omega_{k}$ of adjacent risk factors $c_{k-1}$ and $c_{k}$ according to Table 5 .
TABLE 5: The value of relative importance of criteria.

\begin{tabular}{lc}
\hline$r_{k}$ & Description \\
\hline 1.0 & $c_{k-1}$ is the same important as $c_{k}$ \\
1.2 & $c_{k-1}$ is slightly more important than $c_{k}$ \\
1.4 & $c_{k-1}$ is more important than $c_{k}$ \\
1.6 & $c_{k-1}$ is strongly more important than $c_{k}$ \\
1.8 & $c_{k-1}$ is extremely more important than $c_{k}$ \\
\hline
\end{tabular}

Step 3. Calculate the subjective weights of risk factors by

$$
\begin{aligned}
\omega_{k} & =\left(1+\sum_{k=2}^{n} \prod_{i=k}^{n} r_{k}\right), \\
\omega_{k-1} & =\omega_{k} * r_{k} .
\end{aligned}
$$

Considering experts in Table 2 owning the voting right, the final weights are determined by the calculation result and $m$ decision-makers' weights according to

$$
\omega_{k}^{\prime}=\frac{\omega_{1 k}+\omega_{2 k}+\cdots+\omega_{m k}}{m} .
$$

3.2.2. Objective Weights Using the Entropy Method. The concept of entropy, introduced by Shannon in 1948, is mainly used to measure the uncertainty in information. In the decisionmaking process, the entropy is used to analyze the information quantity provided by data [19]. Therefore, the entropy method can objectively evaluate the importance of risk factors according to the information entropy. The risk factor with higher information entropy should be given higher weight. According to this principle, the specific steps of the entropy method to determine the weights of risk factors are as follows:

Step 1. Construct decision matrix $B=\left(b_{L k}\right)_{m \times n}$, where $b_{L k}$ represent the $k$ th risk weight given by $L$ th expert.

Step 2. Calculate the information entropy of $k$ th risk by

$$
\left\{\begin{array}{l}
H_{k}=-\frac{1}{\ln m} \sum_{L=1}^{m} r_{L k} \ln r_{L k} \\
r_{L k}=\frac{b_{L k}}{\sum_{L=1}^{m} b_{L k}}
\end{array}\right.
$$

Step 3. Determine the objective weights of $\mathrm{k}^{\text {th }}$ risk factor by

$$
w_{k}^{\prime \prime}=\frac{1-H_{k}}{n-\sum_{k=1}^{n} H_{k}} .
$$

3.2.3. Combined Weights on the Basis of Lagrange Theory. Combining the G1 method with the entropy method, the combined weight method integrates professional opinions of experts in the G1 method and uses the entropy objective weight method to avoid subjective errors, which make the final risk factor weight more scientific and reasonable. Under the condition that $w_{k}^{\prime}$ and $w_{k}$ are known, this paper builds an optimization model based on Lagrange theory to achieve the 
combined weights of risk factors. The combined weight model is shown in

$$
w_{k}^{*}=\alpha w_{k}^{\prime}+\beta w_{k}^{\prime \prime}
$$

where $\alpha$ and $\beta$, respectively, represent the proportion of subjective and objective weight. Moreover, $\alpha$ and $\beta$ meet the following conditions in

$$
\begin{cases}\max & F(\alpha, \beta)=\sum_{l=1}^{m}\left(\sum_{k=1}^{n}\left(\alpha w_{k}^{\prime}+\beta w_{k}^{\prime \prime}\right)\right) \\ \text { s.t. } & \alpha^{2}+\beta^{2}=1 .\end{cases}
$$

Furthermore, $\alpha$ and $\beta$ can be achieved using Lagrange functions, which are shown in

$$
\left\{\begin{array}{l}
\alpha=\frac{\sum_{l=1}^{m} \sum_{k=1}^{n} w_{k}^{\prime} x_{l k}}{\sqrt{\left(\sum_{l=1}^{m} \sum_{k=1}^{n} w_{k}^{\prime} x_{l k}\right)^{2}+\left(\sum_{l=1}^{m} \sum_{k=1}^{n} w_{k}^{\prime \prime} x_{l k}\right)^{2}}}, \\
\beta=\frac{\sum_{l=1}^{m} \sum_{l=1}^{n} w_{k}^{\prime \prime} x_{l k}}{\sqrt{\left(\sum_{l=1}^{m} \sum_{k=1}^{n} w_{k}^{\prime} x_{l k}\right)^{2}+\left(\sum_{l=1}^{m} \sum_{k=1}^{n} w_{k}^{\prime \prime} x_{l k}\right)^{2}}} .
\end{array}\right.
$$

\section{Risk Evaluation with D-S Evidence Theory}

Evidence theory was first proposed by Dempster in 1967 and then further developed by Shafer on the basis of Bayes theory in 1976. This theory can carry out credibility reasoning based on uncertain information, has the ability to directly express "uncertainty" and "don't know," and also has strong data fusion ability, which has been widely used in the field of "evaluation" $[17,20,21]$. When D-S evidence theory is used for evaluation, the basic belief degree directly determines the accuracy of the evaluation. Most of the existing research studies take the probability of each of the risk level as the basic belief degree [22]. However, the accuracy of this method to determine the basic belief degree needs to be improved. Due to the existence of uncertain information, the rigor of data can produce a discount effect. The paper believes that it is more reasonable to adjust the data with the discount rate to get the basic belief degree.

Before applying DEST in overall risk level evaluation, we define the discernment frame $\Theta$. $A=\left\{A_{1}, A_{2}, A_{3}, A_{4}, A_{5}\right\}$ represents 5 first-level risk factors. And $n$ risk evaluation factors in $A_{1}$ are expressed as $A_{1}=\left\{c_{1}, c_{2}, \ldots, c_{n}\right\}$. $A_{2}, A_{3}, A_{4}$, and $A_{5}$ are shown in the same way. The following operations present risk calculation processes in sewage treatment PPPABS projects:

Step 1: determine the discount rate $\alpha_{i}$ for the basic belief degree of each risk factor.

Based on the weight vector of each risk factor obtained through the combination weight method mentioned above, $w_{\max }^{*}=\max \left\{w_{1}^{*}, w_{2}^{*}, \ldots, w_{n}^{*}\right\}$ and relative weight vector of each risk factor $W^{\prime}=\left(w_{1}^{*}, w_{2}^{*}, \ldots, w_{n}^{*}\right) / w_{\max }^{*}$ are achieved. Then, the discount rate $\alpha_{i}$ for the basic belief degree of each risk factor is presented in

$$
\alpha_{i}=1-\frac{w_{1}^{*}}{w_{\max }^{*}}, \quad i=1,2, \ldots, n
$$

Step 2: calculate new basic belief degree of each risk factor and improve belief function.

After collecting experts' distribution of the basic belief degree of each risk factor (namely, $m_{i}\left(A_{j}\right)$, where $m$ is the number of experts, the basic belief degree of each risk factor is adjusted by using the discount rate $\alpha_{i}$. The calculation equations are

$$
\begin{aligned}
& m_{i}^{\prime}\left(A_{j}\right)=\left(1-\alpha_{i}\right) m_{i}\left(A_{j}\right), \\
& m^{\prime} \Theta=\left(1-\alpha_{i}\right) m(\Theta)+\alpha_{i},
\end{aligned}
$$

where $j=1,2, \ldots, d_{i}$ and $d_{i}$ is the number of basic belief degree out of discernment frame $\Theta$.

Then, the improved belief function becomes

$$
\operatorname{Bel}^{\prime}(A)=\sum_{B \subseteq A} m(A), \quad \forall A \subseteq \Theta .
$$

Step 3: construct fusion basic belief functions of risk factors.

According to the Dempster combinational rule, there are two fusion patterns:

(1) Fuse two risk factors: if belief functions of two independent risk factors are $m_{1}^{\prime}$ and $m_{2}^{\prime}$, respectively, based on the same discernment frame $\Theta$, the basic belief function $m^{\prime}$ after fusing $m_{1}^{\prime}$ and $m_{2}^{\prime}$ is expressed as

$$
\left\{\frac{m^{\prime}(A)=m_{1}^{\prime}(A) \oplus m_{2}^{\prime}(A)=\sum_{X \cap Y=A} m_{1}^{\prime}(X) \times m_{2}^{\prime}(Y)}{\left(1-\sum_{X \cap Y=\varnothing} m_{1}^{\prime}(X) \times m_{2}^{\prime}(Y)\right),}, \quad A \neq \varnothing, A \subseteq \Omega m^{\prime} \varnothing=0\right.
$$

where $\oplus$ is called "direct sum" representing the combinational operation between factors.

(2) Fuse multiple risk factors: if belief functions of $p(p>2)$ independent risk factors are $m_{1}^{\prime}, m_{2}^{\prime}$, and $m_{p}^{\prime}$, respectively, based on the same discernment frame $\Theta$, the belief function $m$ ' after fusing $m_{1}^{\prime}, m_{2}^{\prime}, \ldots, m_{p}^{\prime}$ is expressed as $\left\{m^{\prime}(A)=m_{1}^{\prime}(A) \oplus m_{2}^{\prime}(A) \oplus \cdots \oplus m_{\mathrm{P}}^{\prime}(A), \quad A \neq \varnothing, A \subseteq \Omega m^{\prime}(\varnothing)=0\right.$. 
Because the Dempster combinational rule has commutativity and associativity, $p(p>2)$ risk factors requires $p-1$ fusion process according to the fusion formula of two factors, and the final result is independent of the fusion order. It can be understood as

$$
m^{\prime}(A)=\sum_{\cap A_{i}=A} \frac{\prod_{i=1}^{m^{\prime}} m_{i}^{\prime}\left(A_{i}\right)}{1-\sum_{\cap A_{i}=\varnothing} \prod_{i=1}^{m^{\prime}} m_{i}^{\prime}\left(A_{i}\right)} .
$$

Step 4: calculate the adjusted basic belief degree. Using $m^{\prime}\left(x_{h}\right)$ and fusion basic belief function belief degree of each risk factor, the adjusted basic belief degree is obtained by the following:

$$
\operatorname{Bel}^{\prime}(A)=\sum_{B \subseteq A} m^{\prime}(A), \quad \forall A \subseteq \Theta .
$$

Step 5: calculate the overall risk value by

$$
R=\sum_{h=1}^{k} P x_{h} \operatorname{Bel}^{\prime}\left(x_{h}\right)
$$

where $P\left(x_{h}\right), h=1,2, \ldots, k$ is the hazard degree of the risk level $x_{k}, P\left(x_{h}\right)$ is gained usually by taking its average, and the value range is $0<P\left(x_{h}\right)<1$.

\section{Case Study}

In this section, the proposed method based on the combination weight method and D-S evidence theory is applied to a case study, which is based on a real project. The name of the case is Beijing capital Co. Ltd. sewage treatment PPPABS project in China. Beijing capital Co. Ltd. and CITIC securities officially launched the sale of PPPABS product in Shanghai stock exchange on March 10, 2017. The product name is "CITIC securities-Beijing capital Co. Ltd. charge income right-backed asset special plan for the sewage treatment PPP project." The original stakeholders of the special plan are four water companies in Shandong province which are wholly-owned subsidiaries of Beijing capital Co. Ltd. The basic assets are the sewage treatment charge income rights owned by the four water utilities under the PPP agreement. Beijing capital Co. Ltd. serves as an asset service agency. The special plan for the sewage treatment project is 530 million yuan, of which 500 million yuan is the priority asset-backed securitization and the remaining 30 million yuan is the secondary asset-backed securitization.

The main steps of the proposed method to implement risk evaluation of Beijing capital Co. Ltd sewage treatment PPPABS are divided into two phases. One phase is that weights of first-level risks and second-level risks are determined through the combination weight method. Another phase is that the overall risk evaluation is realized by D-S evidence theory.

Phase 1. Determine weights of first-level risks and secondlevel risks using the combination weight method.
Firstly, based on their experience and knowledge, 10 experts in Table 2 firstly endow each risk value according to the risk degree in Table 4 and the value of relative importance of criteria in Table 5.

Secondly, to insure the feasibility and effectiveness of the proposed method in the sewage treatment PPPABS project, the data collected from 10 experts are deposed to test reliability. Here, Cronbach's alpha method is applied to test reliability and consistency of the survey data. According to the results and frequencies of data acquisition, three Cronbach's alpha values $(0.866,0.872$, and 0.869$)$, all falling between 0.8 and 0.9 , manifest that the internal consistency is good [23], that is to say, the data from the questionnaire is deemed consistent and reliable.

Finally, subjective weights are calculated based on the G1 method mentioned above, and objective weights are also obtained using the entropy by equations (1)-(5). Finally, combined weights are achieved by equations (6)-(8). Related results are shown in Table 6.

Phase 2. Evaluate overall risk using D-S evidence theory.

Step 1. Obtain the basic belief degree and $\Theta$.

Through expert voting, the voting results of 10 experts on risk index $c_{k}$ at risk level $x_{h}(h=1,2, \ldots, 5)$ is obtained, namely, the basic belief degree of each risk factor $m_{i k}\left(x_{h}\right)$, where $\Theta$ expresses that the level of risk indicator is difficult to be determined by experts. The voting results are presented in Table 7.

Step 2. Determine the discount rate for the basic belief degree of each risk factor.

Because some experts believe that the level of some risk factors is not easy to determine, there is a certain "discount" effect on data rigor. The discount rate equation (9) is used to adjust the data. The discount rate of each level is also shown in Table 7.

Step 3. Calculate fusion basic belief degree of risk factors $\left(m_{i}^{\prime}\left(x_{h}\right)\right)$.

Adjusted basic belief degree of risk factors are achieved by using the discount rate equation (9). Then, the fusion basic belief degree of risk factors $m_{i}^{\prime}\left(x_{h}\right)$ is obtained by applying equations (13)-(15). The calculating results are displayed in Table 8.

Step 4. Determine the risk level probability of overall risk. Once again, the belief degree (in Table 8) is adjusted using equations (10) and (11). Then, the adjusted belief degree is fused by equations (13) and (14). Finally, the risk level probability of the overall risk is determined, which is shown in Table 9.

Step 5. Calculate the overall risk value. 
TABLE 6: Weights of first-level risks and second-level risks.

\begin{tabular}{|c|c|c|c|c|c|}
\hline First-level risk factors & Weight & Second-level risk factors & Subjective weight & Objective weight & Combined weight \\
\hline \multirow{3}{*}{$A_{1}$} & \multirow{3}{*}{0.2534} & $C_{1}$ & 0.040 & 0.042 & 0.0410 \\
\hline & & $C_{2}$ & 0.050 & 0.045 & 0.0470 \\
\hline & & $C_{3}$ & 0.167 & 0.164 & 0.1654 \\
\hline \multirow{4}{*}{$A_{2}$} & \multirow{4}{*}{0.1249} & $\mathrm{C}_{4}$ & 0.045 & 0.042 & 0.0434 \\
\hline & & $C_{5}$ & 0.031 & 0.034 & 0.0327 \\
\hline & & $\mathrm{C}_{6}$ & 0.022 & 0.029 & 0.0259 \\
\hline & & $C_{7}$ & 0.019 & 0.026 & 0.0229 \\
\hline \multirow{3}{*}{$A_{3}$} & \multirow{3}{*}{0.1867} & $C_{8}$ & 0.127 & 0.125 & 0.1259 \\
\hline & & $C_{9}$ & 0.017 & 0.016 & 0.0165 \\
\hline & & $C_{10}$ & 0.047 & 0.042 & 0.0443 \\
\hline \multirow{3}{*}{$A_{4}$} & \multirow{3}{*}{0.1352} & $C_{11}$ & 0.057 & 0.059 & 0.0581 \\
\hline & & $C_{12}$ & 0.037 & 0.035 & 0.0359 \\
\hline & & $C_{13}$ & 0.044 & 0.039 & 0.0413 \\
\hline \multirow{4}{*}{$A_{5}$} & \multirow{4}{*}{0.2998} & $C_{14}$ & 0.191 & 0.195 & 0.1932 \\
\hline & & $C_{15}$ & 0.036 & 0.033 & 0.0344 \\
\hline & & $C_{16}$ & 0.029 & 0.028 & 0.0285 \\
\hline & & $C_{17}$ & 0.041 & 0.046 & 0.0438 \\
\hline
\end{tabular}

Table 7: The basic belief degree, $\Theta$, and discount rate.

\begin{tabular}{|c|c|c|c|c|c|c|c|c|c|c|}
\hline \multirow{2}{*}{ First-level risk factors } & \multirow{2}{*}{ Weight } & \multirow{2}{*}{ Second-level risk factors } & \multirow{2}{*}{ Combined weight } & \multicolumn{5}{|c|}{ Basic belief degree } & \multirow{2}{*}{$\Theta$} & \multirow{2}{*}{$\alpha_{i}$} \\
\hline & & & & $x_{1}$ & $x_{2}$ & $x_{3}$ & $x_{4}$ & $x_{5}$ & & \\
\hline \multirow{3}{*}{$A_{1}$} & \multirow{3}{*}{0.2534} & $C_{1}$ & 0.0410 & 0.2 & 0.2 & 0.2 & 0.1 & 0.2 & 0.1 & 0.7878 \\
\hline & & $\mathrm{C}_{2}$ & 0.0470 & 0.1 & 0.2 & 0.3 & 0.1 & 0.3 & 0 & 0.7567 \\
\hline & & $C_{3}$ & 0.1654 & 0.1 & 0.3 & 0.3 & 0.2 & 0.1 & 0 & 0.1439 \\
\hline \multirow{4}{*}{$A_{2}$} & \multirow{4}{*}{0.1249} & $C_{4}$ & 0.0434 & 0.2 & 0.1 & 0.3 & 0.2 & 0.2 & 0.1 & 0.7754 \\
\hline & & $C_{5}$ & 0.0327 & 0.2 & 0.3 & 0.2 & 0.1 & 0.2 & 0 & 0.8307 \\
\hline & & $\mathrm{C}_{6}$ & 0.0259 & 0.1 & 0.1 & 0.3 & 0.3 & 0.2 & 0.1 & 0.8659 \\
\hline & & $\mathrm{C}_{7}$ & 0.0229 & 0.1 & 0.1 & 0.2 & 0.3 & 0.4 & 0 & 0.8815 \\
\hline \multirow{3}{*}{$A_{3}$} & \multirow{3}{*}{0.1867} & $C_{8}$ & 0.1259 & 0.0 & 0.2 & 0.2 & 0.3 & 0.2 & 0 & 0.3483 \\
\hline & & $C_{9}$ & 0.0165 & 0.2 & 0.4 & 0.2 & 0.1 & 0.1 & 0 & 0.91460 \\
\hline & & $C_{10}$ & 0.0443 & 0.1 & 0.2 & 0.3 & 0 & 0.2 & 0.2 & 0.7707 \\
\hline \multirow{3}{*}{$A_{4}$} & \multirow{3}{*}{0.1352} & $C_{11}$ & 0.0581 & 0.1 & 0.2 & 0.3 & 0.1 & 0.3 & 0 & 0.6993 \\
\hline & & $C_{12}$ & 0.0359 & 0.2 & 0.2 & 0.2 & 0.2 & 0.1 & 0.1 & 0.8142 \\
\hline & & $C_{13}$ & 0.0413 & 0 & 0.1 & 0.4 & 0.3 & 0.2 & 0 & 0.7862 \\
\hline \multirow{4}{*}{$A_{5}$} & \multirow{4}{*}{0.2998} & $C_{14}$ & 0.1932 & 0.3 & 0.2 & 0.1 & 0.2 & 0.1 & 0.1 & 0 \\
\hline & & $C_{15}$ & 0.0344 & 0.1 & 0.1 & 0.2 & 0.5 & 0.1 & 0.1 & 0.8219 \\
\hline & & $C_{16}$ & 0.0285 & 0.2 & 0.1 & 0.3 & 0.1 & 0.3 & 0 & 0.8525 \\
\hline & & $C_{17}$ & 0.0438 & 0 & 0.1 & 0.3 & 0.4 & 0.2 & 0 & 0.7733 \\
\hline
\end{tabular}

TABle 8: Fusion basic belief degree of risk factors.

\begin{tabular}{|c|c|c|c|c|c|c|}
\hline \multicolumn{2}{|c|}{$\begin{array}{l}\text { First-level } \\
\text { risk factors }\end{array}$} & $A_{1}$ & $A_{2}$ & $A_{3}$ & $A_{4}$ & $A_{5}$ \\
\hline \multicolumn{2}{|l|}{ Weight } & 0.2624 & 0.1928 & 0.2206 & 0.2174 & 0.1069 \\
\hline \multirow{6}{*}{$m_{i}^{\prime}\left(x_{h}\right)$} & $x_{1}$ & 0.0227 & 0.2990 & 0.0115 & 0.0321 & 0.3981 \\
\hline & $x_{2}$ & 0.5707 & 0.3657 & 0.1552 & 0.0951 & 0.3611 \\
\hline & $x_{3}$ & 0.3293 & 0.2161 & 0.2736 & 0.5319 & 0.2408 \\
\hline & $x_{4}$ & 0.0566 & 0.0397 & 0.5596 & 0.3205 & 0.0000 \\
\hline & $x_{5}$ & 0.0206 & 0.0794 & 0.0000 & 0.0183 & 0.0000 \\
\hline & $\Theta$ & 0.0000 & 0.0000 & 0.0000 & 0.0021 & 0.0000 \\
\hline
\end{tabular}

TABLE 9: Risk level probability of overall risk.

\begin{tabular}{lccccc}
\hline$x_{1}$ & $x_{2}$ & $x_{3}$ & $x_{4}$ & $x_{5}$ & $\Theta$ \\
\hline 0.0027 & 0.0066 & 0.0635 & 0.5406 & 0.3861 & 0.0005
\end{tabular}

Table 10: Risk level hazard degree.

\begin{tabular}{lllll}
\hline$P_{x_{1}}$ & $P_{x_{2}}$ & $P_{x_{3}}$ & $P_{x_{4}}$ & $P_{x_{5}}$ \\
\hline 1 & 0.77 & 0.52 & 0.30 & 0.15 \\
\hline
\end{tabular}


According to the opinions of 10 experts, the hazard degree of the corresponding risk level is classified, and the values of hazard degree $P(X)$ are given in Table 10 .

Then, the overall risk value $R$ is calculated by using equations (16) and (17). The calculating process and result are

$$
\begin{aligned}
R= & \sum_{h=1}^{k} P x_{h} \operatorname{Bel}^{\prime}\left(x_{h}\right)=1 * 0.0027+0.77 * 0.0066+0.52 \\
& * 0.0640+0.3 * 0.5406+0.15 * 0.3861=0.2612
\end{aligned}
$$

\section{Discussion and Suggestion}

As shown in Table 9, overall risk level probability of uncertainty $(0.005)$ indicates that D-S evidence theory could help to reduce the uncertainty. Moreover, overall risk level probabilities in "Very High," "High", "Moderate," "Low," and "Very Low" are 0.002, 0.0066, 0.0635, 0.5406, and 0.3861 , respectively, which imply few risk factors in "Very High" and "High" and almost risk factors in "Low" and "Very Low." The final result (0.2612) also confirms the situation and more indicates the overall risk level of Beijing Capital Co. Ltd. sewage treatment PPPABS project is "Low." The above results are consistent with the actual situation of Beijing Capital Co. Ltd. sewage treatment PPPABS project, which proves that the proposed method is feasible and reliable for the risk evaluation of sewage treatment PPPABS projects, and could play an important role in the risk prediction.

However, 0.2612 shows that Beijing Capital Co. Ltd. sewage treatment PPPABS project still has a certain risk. Based on each risk factor's combined weight in Table 6 and basic belief degree in Table 7, we provide the following suggestions to ensure sewage treatment PPPABS projects success. Suggestions would be made from low risk, quality risk, underwriting and issue risk, and credit enhancement.

6.1. Law Risk Aspect. Because the current laws and regulations of ABS are not perfect, it is easy to have the risk of contract agreement invalidation, legal uncertainty, and legal clause change. Government sector should take measures as soon as possible from the following. (i) Before special legislation is introduced, the supreme court can be considered to formulate relevant judicial interpretations to solve legal problems. (ii) The supervision subject and principle of ABS should be clarified, and the company law, bankruptcy law, and securities law should be improved as quickly as possible. (iii) We can draw lessons from the successful experience to develop a legal system suitable for PPP project asset-backed securitization.

6.2. Quality Risk Aspect. The basic asset quality of PPPABS projects must meet certain conditions, or it may cause security risks in the beginning of securitization. Basic assets should be rigorously screened. (i) The basic assets should be subjected to strict examination and approval. Not all public infrastructures have stable cash flow. PPP projects that implement $\mathrm{ABS}$ must require the predictability of future cash flow and clearly defined payment patterns. (ii) The project company's construction quality should meet certain standards. Firstly, the project has continuous safe and stable operation. Secondly, the project has been completed and normal operation for more than 2 years. Finally, the project has established a reasonable return on investment mechanism and moreover has strong performance ability.

6.3. Underwriting and Issuing Risk Aspect. The underwriting and issue of securities are the important links in the process of PPPABS. Some necessary measures should be taken to deal with the underwriting and issue risk. (i) In the design of securities issuance, bonds can be designed with different maturities and currencies, as well as different types of bonds according to the credit rating results, so as to match the risks with the returns. Only after the investigation and analysis of the market can the reasonable price of the stock be determined. (ii) The underwriter should participate in the planning and organization of the issuing securities to ensure that the issuing process complies with the requirements of laws and regulations. At the same time, underwriters are required to expand marketing channels to guarantee the success of the issuing securities. (iii) Based on the market situation and the characteristics of investors' demand, the underwriting way should be chosen prudently. If the risk is small in the future, we can take the commission. Otherwise, we can choose to underwrite.

6.4. Credit Enhancement. The purpose of credit enhancement is to prevent the credit risk in the process of assetbacked securitization, but it also has own risks. There is a risk that internal credit enhancement will not be fully isolated from the originator's assets. External credit enhancement may result in a decline in credit rating of the securitization transaction as a result of a reduction in credit rating of the credit enhancement institution itself. For credit enhancement risk, we should take countermeasures. (i) The assets with internal credit enhancement should be estimated by the asset appraisal agency, and the necessary audit also should be conducted to ensure the safety of the assets. (ii) We should choose commercial banks and insurance companies with good reputation and stable operation as external credit enhancement institutions to ensure effective credit enhancement.

\section{Conclusion}

Sewage treatment PPP projects can play an important role in achieving a clean environment and promoting sustainable development. With the strong support of the government, the ABS mode has been introduced into sewage treatment PPP projects to overcome the imbalance between supply and demand. It is an effective way to attract private capital and improve sewage treatment performance and service. Risk research of sewage treatment PPPABS projects is necessary 
to ensure project success and it is important to achieve what risk factors affect the sewage treatment PPPABS projects and how to calculate the overall risk using the scientific method. To solve this problem, this paper establishes a risk identification and evaluation framework for sewage treatment PPPABS projects with the combination weight method and D-S evidence theory. As the results, 17 critical risk factors are selected as the evaluation system by literature review and expert interview. And, we determine risk factors' weights with the combination weight method (the G1 method being combined with the entropy) and evaluate the overall risk of sewage treatment PPPABS projects with D-S evidence theory. Suggestion are put forward to effectively control risks and further to guarantee sewage treatment PPPABS projects success. Risk evaluation of PPPABS projects is the focus of current research and attracts much attention from researchers. As a core part of financing risk management, risk evaluation of sewage treatment PPPABS projects plays an important role though little literature has carried out careful identification of its risk factors and overall risk evaluation. This paper attempts to contribute to this section.

This study also has limitations and shortcomings. Due to inadequate experience in sewage treatment PPPABS projects, risk system cannot be perfect. The availability of collected risk data should be more accurate and feasible. In the next study, identification methods of risk factors can be innovated. Additionally, this study proposed the risk evaluation method using the combination weight method and $\mathrm{D}$-S evidence theory, which is proved to be feasible and reliable. Next, comparative studies based on other risk evaluation methods can be discussed.

\section{Data Availability}

No data are used to support this study.

\section{Conflicts of Interest}

The authors declare that there are no conflicts of interest regarding the publication of this paper.

\section{Acknowledgments}

The authors thank the National Natural Science Foundation of China (Grant no. 71471094).

\section{References}

[1] J. Liu and Q. Wei, "Risk evaluation of electric vehicle charging infrastructure public-private partnership projects in China using fuzzy TOPSIS," Journal of Cleaner Production, vol. 189, pp. 211-222, 2018.

[2] J. Song and L. Zhang, "Study on dynamic income distribution of sewage treatment PPP project," Construction Economy, vol. 40, no. 9, pp. 46-51, 2019.

[3] J. Zhang, Z. Qiu, and L. Fei, "An exploration of comprehensive evaluation method of sewage treatment construction project in small and medium towns: theory and application," Desaling and Water Treatment, vol. 118, pp. 70-78, 2018.
[4] H. Li, L. Ding, C. Li, and H. Wang, "Sponge city construction in China: a survey of the challenges and opportunities," Water, vol. 9, no. 9, p. 594, 2017.

[5] S. Cheng, M. Zhao, X. Zhou, and Z. Li, "Development and application of biogas project for domestic sewage treatment in rural China: opportunities and challenges," Journal of Water, Sanitation and Hygiene for Development, vol. 7, no. 4, pp. 576-588, 2017.

[6] J. Song, L. Chen, and X. Guan, "Research on risk sharing of PPP plus EPC sewage treatment project based on bargaining game mode," Fresenius Environmental Bulletin, vol. 29, no. 2, pp. 903-912, 2020.

[7] L. Qian, Z. Liao, and Q. Guo, "Effects of short-term uncertainties on the revenue estimation of PPP sewage treatment projects," Water, vol. 11, no. 6, pp. 1-14, 2019.

[8] A. A. Farooquee, "Design, structure, and risk assessment of a pre-securitization financing facility for rooftop solar projects in India," The Journal of Structured Finance, vol. 23, no. 1, pp. 91-97, 2017.

[9] Z. Lu, F. Pena-Mora, S. Q. Wang, T. Liu, and D. Wu, “Assessment framework for financing public-private partnership infrastructure projects through asset-backed securitization," Journal of Management In Engineering, vol. 35, no. 6, pp. 40-56, 2019.

[10] J. C. Shenker and A. J. Colletta, "Asset securitization: evolution, current issues and new frontiers," Texas Law Review, vol. 69, no. 6, p. 1374, 1991.

[11] S. Liang, "Chinese credit asset securitization: development status, problems and suggestions," International Business and Management, vol. 3, pp. 75-80, 2015.

[12] Y. Hou, "Risk analysis and evaluation of PPP asset securitization based on the whole process," Finance and Accounting Monthly, vol. 9, pp. 79-86, 2018, in Chinese.

[13] Y. Liu, S. Gan, and S. Zhao, "Research on the construction of risk evaluation system of asset-backed securitization in PPP projects," Statistics and Decision, vol. 11, pp. 161-163, 2019, in Chinese.

[14] P. Liu and Y. Shao, "Small business loan securitization and interstate risk sharing," Small Business Economics, vol. 41, no. 2, pp. 449-460, 2013.

[15] T. Lyons and S. Martin, "Project risk management in the Queensland engineering construction industry: a survey," International Journal of Project Management, vol. 22, no. 1, pp. 51-61, 2004.

[16] F. Y. Meng, J. Tang, S. L. Zhang, and Y. W. Xu, "Public-private partnership decision making based on correlation coefficients of single-valued neutrosophic hesitant fuzzy sets," Informatica, vol. 31, no. 2, pp. 359-397, 2020.

[17] P. Liu and X. Zhang, "Approach to multi-attributes decision making with intuitionistic linguistic information based on dempster-shafer evidence theory," IEEE Access, vol. 6, pp. 52969-52981, 2018.

[18] B. Liu and Y. Hu, "Critical factors of effective public participation in sustainable energy projects," Journal of Management in Engineering, vol. 34, no. 5, Article ID 04018029, 2018.

[19] R. Osei-Kyei and A. P. C. Chan, "Review of studies on the critical success factors for public-private partnership (PPP) projects from 1990 to 2013," International Journal of Project Management, vol. 33, no. 6, pp. 1335-1346, 2015.

[20] F. Xu, J. Liu, S. Lin, and J. Yuan, “A VIKOR-based approach for assessing the service performance of electric vehicle sharing programs: a case study in Beijing," Journal of Cleaner Production, vol. 148, pp. 254-267, 2017. 
[21] J. W. Godden, F. L. Stahura, and J. Bajorath, "Variability of molecular descriptors in compound databases revealed by Shannon entropy calculations," Journal of Chemical Information and Computer Sciences, vol. 40, no. 3, pp. 796-800, 2000.

[22] L. Wang, G. Zhang, and Q. Hao, "Risk evaluation of cold chain marine logistics based on the dempster-shafer (D-S) evidence theory and radial basis function (RBF) neural network," Journal of Coastal Research, vol. 98, no. sp1, pp. 376-380, 2019.

[23] D. George and M. Mallery, Using SPSS for Windows Step by Step: A Simple Guide and Reference, Allyn \& Bacon, Boston, MA, USA, 2003. 